\title{
Propriedades Térmicas de Compósitos de Polipropileno e Bentonita Organofílica
}

\author{
Elaine V. D. G. Líbano \\ Departamento de Tecnologia em Polímeros, UEZO \\ Leila L. Y. Visconte, Élen B. A. V. Pacheco \\ Instituto de Macromoléculas Professora Eloisa Mano, UFRJ
}

\begin{abstract}
Resumo: Uma argila bentonita policatiônica nacional foi utilizada para a produção de uma argila organofílica, obtida a partir da síntese com o sal de amônio quaternário, cloreto de cetiltrimetilamônio. A argila tratada com o sal orgânico (BENT-org) e a não tratada (BENT) foram caracterizadas por espectroscopia de absorção no infravermelho (FTIR) e difratometria de raios X (DRX). Posteriormente, as argilas foram misturadas com o polipropileno (PP) pelo método de intercalação por fusão em uma extrusora dupla-rosca co-rotativa. Os compósitos foram caracterizados pelas técnicas de DRX, calorimetria diferencial de varredura (DSC) e análise termogravimétrica (TGA). Os resultados de FTIR e DRX mostraram a presença dos grupos característicos do sal de amônio e a intercalação deste entre as camadas do argilomineral. As análises de DRX dos compósitos com 3 e 5\% em massa de BENT-org evidenciaram a presença de picos deslocados para regiões de baixo ângulo, sugerindo a intercalação das cadeias do polímero entre as camadas da argila. Os resultados de DSC indicaram que a argila pode ter atuado como agente nucleante devido ao aumento na $\mathrm{T}_{\text {cc }}$ (temperatura de cristalização no resfriamento) dos compósitos. De acordo com os resultados de TG, constatou-se que a incorporação da argila ao PP melhorou a estabilidade térmica do polímero nos compósitos com 5\% em massa de BENT e 3 e 5\% em massa de BENT-org.
\end{abstract}

Palavras-chave: Bentonita organofílica, polipropileno, compósitos.

\section{Thermal Properties of Polypropylene and Organophilic Bentonite}

\begin{abstract}
A Brazilian polycationic bentonite clay was used for producing an organophilic clay with the quaternary ammonium salt, cetyltrimethylammonium chloride. The salt treated clay (BENT-org) and untreated clay (BENT) were characterized by infrared spectroscopy (FTIR) and X-ray diffraction (XRD). Then, each clay was mixed with polypropylene (PP) by melt intercalation in a counterrotating twin-screw extruder. The composites were characterized by XRD, differential scanning calorimetry (DSC) and thermogravimetric analysis (TGA). The results from FTIR and XRD showed the presence of specific groups of the ammonium salt and their intercalation in between the clay layers. XRD analyses of the composites with 3 and 5 wt. (\%) of BENT-org revealed peaks displaced towards smaller angles, suggesting the intercalation of the chain polymer into the clay layers. DSC results indicated that the clay may have acted as a nucleating agent as seen from the increase in the $\mathrm{T}_{\mathrm{cc}}$ (crystallization temperature in the cooling) of the composites. Consistent with the TG results, the incorporation of clay into PP improved the thermal stability of the polymer in the composites with 5 wt. (\%) of BENT and 3 and 5 wt. (\%) of BENT-org.
\end{abstract}

Keywords: Organophilic bentonite, polypropylene, composites.

\section{Introdução}

Os compósitos surgiram como uma alternativa para melhorar propriedades específicas de polímeros já existentes ou modificá-las através da adição de outros materiais. Eles são uma classe de materiais multifásicos, podendo ou não ser poliméricos. Nesses materiais, um dos componentes, descontínuo, fornece a principal resistência ao esforço (componente estrutural ou reforço) e o outro, contínuo, é o meio de transferência desse esforço (componente contínuo ou matricial $)^{[1]}$.

A incorporação de cargas inorgânicas em polímeros oferece as vantagens dos materiais orgânicos, tais como baixa densidade, flexibilidade e facilidade de moldagem, e as dos inorgânicos, como altas resistências química e mecânica, e estabilidade térmica. As cargas de dimensões nanométricas (1-500 nm) apresentam uma área superficial elevada, promovendo melhor dispersão na matriz polimérica e, por isso, uma melhoria nas suas propriedades físicas, as quais dependem da homogeneidade da mistura final. A preparação de compósitos de matriz polimérica com cargas nanométricas permite, em muitos casos, obter um material com um baixo custo, devido à utilização de menor quantidade de carga, e um elevado nível de desempenho, que pode resultar da sinergia entre os componentes ${ }^{[2,3]}$.

Uma grande variedade de materiais lamelares pode ser encontrada na natureza, como as argilas (aluminossilicatos), haletos de metais de transição, hidróxidos de metais bivalentes e fosfatos de metais tetravalentes, usados como cargas em compósitos. Os cristais são formados pela sobreposição de lamelas, que estão fracamente unidas por ligações do tipo Van der Waals e ligações de hidrogênio ${ }^{[2]}$.

A bentonita é uma argila constituída essencialmente por um ou mais argilominerais do grupo das esmectitas, especialmente a montmorilonita, não importando qual seja a origem geológica. A bentonita é um aluminossilicato 2:1 [( $\left.\left.\mathrm{Mg}, \mathrm{Ca}) \mathrm{O} \cdot \mathrm{Al}_{2} \mathrm{O}_{3} \mathrm{Si}_{5} \mathrm{O}_{10} \cdot \mathrm{nH}_{2} \mathrm{O}\right)\right]$ formado a partir da decomposição de cinzas vulcânicas. As bentonitas naturais possuem com maior frequiência os cátions trocáveis $\mathrm{Na}^{+}$, $\mathrm{Mg}^{2+}, \mathrm{Ca}^{2+}, \mathrm{Al}^{3+} \mathrm{e} \mathrm{Fe}^{3+}$. A ocorrência mais comum é de bentonitas policatiônicas com predominância de um cátion, a exemplo o $\mathrm{Na}^{+}$nas bentonitas de Wyoming (EUA) ou $\mathrm{Ca}^{2+}$ nas bentonitas do Mississipe $(E U A)^{[4]}$. No Brasil, não se tem conhecimento, até o presente, da existência de bentonitas essencialmente sódicas. Na maioria dos

Autor para correspondência: Elaine V. D. G. Líbano, Departamento de Tecnologia em Polímeros, Centro Universitário Estadual da Zona Oeste - UEZO Av. Manuel Caldeira de Alvarenga, 1203, Campo Grande, CEP 23070-200, Rio de Janeiro, RJ, Brasil, e-mail: elainelibano@uezo.rj.gov.br 
casos, as bentonitas são policatiônicas e contêm teores variados de argilominerais. Dado o interesse tecnológico, a partir das bentonitas policatiônicas, por troca de cátions com composto de sódio ou cálcio, é possível produzir bentonitas sódicas ou cálcicas com propriedades tecnológicas semelhantes às das bentonitas verdadeiras (no sentido geológico), naturalmente sódicas ou cálcicas. A única bentonita brasileira contendo parte aceitável de sódio como cátion trocável está localizada no município de Boa Vista, Estado da Paraíba ${ }^{[5]}$.

Os silicatos são naturalmente hidrofílicos, o que torna difícil a interação e a capacidade de mistura com matrizes poliméricas apolares ${ }^{[6]}$. Sendo assim, o processo de troca iônica é freqüentemente empregado para o desenvolvimento dos nanocompósitos, melhorando a compatibilização entre a argila e a matriz polimérica. Para que os filossilicatos hidrofílicos se tornem organofílicos, os cátions hidratados das intercamadas devem ser trocados. A troca, geralmente, ocorre com surfactantes catiônicos (íons alquilamônio). Essas argilas modificadas (ou organoargila) têm energia superficial menor e são compatíveis com polímeros orgânicos, além de apresentarem um aumento na distância intercamadas (espaço basal, "d-spacing"), o que facilita a intercalação tanto por monômeros quanto por polímeros ${ }^{[7-9]}$

O objetivo deste trabalho é a preparação de compósitos de polipropileno e diferentes teores de bentonita organofílica através do processo de intercalação por fusão, utilizando uma extrusora dupla-rosca co-rotativa. As técnicas de DRX, DSC e TGA foram empregadas para a caracterização morfológica e térmica dos materiais obtidos.

\section{Experimental}

\section{Materiais}

$\mathrm{Na}$ preparação dos compósitos, empregou-se como matriz um polipropileno (PP) fornecido pela Suzano Petroquímica S.A. (Rio de Janeiro, RJ) com índice de fluidez $=3,5 \mathrm{~g} / 10 \mathrm{~min}$ $\left(230{ }^{\circ} \mathrm{C} / 2,16 \mathrm{~kg}\right)$ e densidade $0,905 \mathrm{~g} \cdot \mathrm{cm}^{-3}$. Como carga, utilizouse uma bentonita policationnica (BENT), com capacidade de troca catiônica de $80 \mathrm{mEq} / 100 \mathrm{~g}$, que foi fornecida pela Bentonit União Nordeste (BUN) (Campina Grande, PB). O sal quaternário de amônio usado na síntese da argila organofílica foi o cloreto de cetiltrimetilamônio, fornecido pela Pharmaspecial Especialidades Químicas e Farmacêuticas (Santana de Parnaíba, SP).

\section{Preparação da argila organofílica}

Os cátions inorgânicos presentes na argila BENT foram primeiramente trocados por íons sódio. Nesta reação, foram utilizados $20 \mathrm{~g}$ de argila natural (BENT), $100 \mathrm{~g}$ de $\mathrm{NaCl}$ e $200 \mathrm{~mL}$ de água deionizada. A BENT, o $\mathrm{NaCl}$ e a água foram adicionados em um balão de três bocas com agitador mecânico acoplado à boca central do balão; na outra boca, havia um condensador e, na terceira, um termômetro. O balão foi aquecido por banho de óleo de silicone a $55{ }^{\circ} \mathrm{C}$, sob agitação por 72 horas. Após a retirada da água sobrenadante, a argila resultante da troca cationnica foi transferida para tubos e a solução, centrifugada por 30 minutos na velocidade de $3.500 \mathrm{rpm}$. O produto foi novamente centrifugado com água deionizada (3 L), a fim de remover os ânions $\mathrm{Cl}^{-}$. A ausência de cloreto foi verificada através da reação com uma solução de $\mathrm{AgNO}_{3}$ 0,1 mol. $\mathrm{L}^{-1}$. Em seguida, a argila na forma homo-iônica sódica (BENT-Na) foi seca em estufa com circulação de ar a $60{ }^{\circ} \mathrm{C}$ por 48 horas, para a retirada do excesso de água. $\mathrm{O}$ material final, em quantidade suficiente, foi armazenado em dessecador para a próxima etapa do tratamento. A fim de se obter a argila organofílica utilizando o sal cloreto de cetiltrimetilamônio, preparou-se uma dispersão contendo $20 \mathrm{~g}$ de BENT-Na, $24 \mathrm{~g}$ de cloreto de cetiltrimetilamônio e $400 \mathrm{~mL}$ de água deionizada. A BENT-Na, o cloreto de cetiltrimetilamônio e a água foram adicionados a um balão de três bocas, com um agitador mecânico acoplado à boca central do balão, à outra boca, um condensador e à última, um termômetro. O balão foi aquecido por banho de óleo de silicone a $70{ }^{\circ} \mathrm{C}$, sob agitação, por 72 horas. Em seguida, o produto foi centrifugado com água deionizada (3L) por 30 minutos a velocidade de $3.500 \mathrm{rpm}$, a fim de se remover os ânions $\mathrm{Cl}^{-}$presentes no sal orgânico empregado. A ausência de cloreto foi verificada através da reação com uma solução de $\mathrm{AgNO}_{3} 0,1$ mol.L $\mathrm{L}^{-1}$. Os aglomerados de argila organofílica obtidos foram secos em estufa com circulação de ar a $60{ }^{\circ} \mathrm{C}$, por 48 horas. A desagregação dos aglomerados secos foi realizada com o auxílio de almofariz manual até a obtenção de materiais pulverulentos. O produto final foi, então, armazenado em dessecador para posterior caracterização.

\section{Preparação dos compósitos}

As amostras de argila foram previamente secas em estufa a $60{ }^{\circ} \mathrm{C}$ por 24 horas antes da etapa de extrusão. Os compósitos com a bentonita foram obtidos pela prévia preparação de dois diferentes masterbatches com 25\% em massa de argila: 1) PP e bentonita natural (BENT); e 2) PP e bentonita modificada (BENT-org). Em todos os dois masterbatches as argilas foram adicionadas por um alimentador lateral. Os masterbatches foram preparados em extrusora dupla-rosca co-rotativa (TECK TRIL, model DCT 20) com diâmetro de rosca $20 \mathrm{~mm}$ e $\mathrm{L} / \mathrm{D}=36$, com uma velocidade de $300 \mathrm{rpm}$ e temperaturas de $120^{\circ} \mathrm{C}$ para a zona $1,165^{\circ} \mathrm{C}$ para a zona $2,190{ }^{\circ} \mathrm{C}$ (zonas 3 a 9) e $200{ }^{\circ} \mathrm{C}$ no cabeçote. Posteriormente, a quantidade adequada de PP foi adicionada de modo a tentar se obter as concentrações de 1, 3 e $5 \%$ em massa de argila. A velocidade de processamento e o perfil de temperatura foram os mesmos empregados para a preparação do masterbactch. O material extrudado foi granulado, seco em estufa a $70{ }^{\circ} \mathrm{C}$ por 2 horas e posteriormente, moldado por compressão (à temperatura de $180{ }^{\circ} \mathrm{C}$ sob pressão de $4 \mathrm{t}$ por 5 minutos) em prensa de bancada tipo Carver, para a obtenção dos corpos-de-prova.

\section{Caracterização}

A bentonita natural (BENT), a bentonita sódica (BENT-Na) e a bentonita organofílica (BENT-org) foram caracterizadas por espectroscopia de absorção no infravermelho (FTIR) e difratometria de raios $\mathrm{X}$ (DRX). Já os compósitos, por DRX, calorimetria diferencial de varredura (DSC) e análise termogravimétrica (TGA).

As amostras de bentonita, antes e após a modificação com o $\mathrm{NaCl}$ e com o sal de amônio, foram caracterizadas por FTIR, na forma de pastilhas feitas a partir de $0,007 \mathrm{~g}$ de argila e $0,100 \mathrm{~g}$ de $\mathrm{KBr}$, prensadas a $5 \mathrm{t}$ durante 30 segundos.

Os difratogramas das argilas e de cada compósito foram obtidos em aparelho Rigaku Miniflex com radiação $\mathrm{K} \alpha$ do cobre $(\lambda=1,5418 \AA$ ) $)$, tensão de $40 \mathrm{kV}$, corrente de $40 \mathrm{~mA}$, varredura entre $2 \theta$ de 2 a $35^{\circ}$ e velocidade de varredura $2 \%$ min.

O comportamento térmico e o grau de cristalinidade (X) dos compósitos foram avaliados por calorimetria diferencial de varredura (DSC) em equipamento TA Instruments, modelo DSC Q-1000. As condições de teste foram: fluxo de nitrogênio a $30 \mathrm{~mL} / \mathrm{min}$; aquecimento de -20 a $280{ }^{\circ} \mathrm{C} \mathrm{a} 10^{\circ} \mathrm{C} / \mathrm{min}$; resfriamento de 280 a $-20^{\circ} \mathrm{C}$ a $10^{\circ} \mathrm{C} /$ min e segundo aquecimento de -20 a $280{ }^{\circ} \mathrm{C}$ a $10{ }^{\circ} \mathrm{C} / \mathrm{min}$. A temperatura de cristalização $\left(\mathrm{T}_{c c}\right)$ foi obtida a partir do pico exotérmico obtido no resfriamento. $\mathrm{O}_{\mathrm{c}}$ dos compósitos foi calculado a partir da razão da entalpia de fusão do polipropileno 
presente no compósito pela entalpia de fusão do polipropileno $100 \%$ cristalino $\left(\Delta \mathrm{H}^{\circ}=138{\mathrm{~J} . \mathrm{g}^{-1}}^{[10]}\right.$.

As análises termogravimétricas foram feitas em um Analisador Termogravimétrico (TA Instrument - USA), com taxa de aquecimento $10{ }^{\circ} \mathrm{C} /$ min e temperatura de 25 a $700{ }^{\circ} \mathrm{C}$, sob atmosfera de $\mathrm{N}_{2}$. Além de avaliar a estabilidade térmica dos materiais preparados, esta técnica também foi utilizada para comprovar o teor real de argila nos compósitos. Este teor é representado pela massa residual do ensaio, o qual caracteriza a percentagem de argila incorporada a matriz polimérica.

\section{Resultados e Discussão}

\section{Análise de FTIR}

Na Figura 1 são observados os espectros de FTIR da argila natural (BENT) (A), da argila sódica (BENT-Na) (B) e da BENT após tratamento de organofilização com o cloreto de cetiltrimetilamônio (BENT-org) (C).

Observando o espectro para a BENT (A), verifica-se a presença de dois picos em 3.630 e $3.420 \mathrm{~cm}^{-1}$ referentes à frequência de vibração dos grupos $\mathrm{OH}$ da argila. $\mathrm{O}$ pico em $1.642 \mathrm{~cm}^{-1}$ corresponde às vibrações de $\mathrm{HOH}$. Os picos em 1.040 e em $468 \mathrm{~cm}^{-1}$ estão relacionados com as vibrações características dos grupos $\mathrm{Si}-\mathrm{O}$. Também são observadas as vibrações de deformação Al-OH em $919 \mathrm{~cm}^{-1}$ e vibrações Si-O-Al em 793 e $528 \mathrm{~cm}^{-1[1]}$. Não foram encontradas mudanças no espectro da BENT-Na (B) em relação à $\operatorname{BENT}(\mathrm{A})$.

O espectro da BENT-org (C) apresenta bandas em 2.922 e $2.849 \mathrm{~cm}^{-1}$ correspondente aos estiramentos assimétricos e simétricos de grupos $\mathrm{C}-\mathrm{H}$ (dos grupos $\mathrm{CH}_{3}$ e $\mathrm{CH}_{2}$ ). O pico em $1.480 \mathrm{~cm}^{-1}$ é atribuído às vibrações de flexão dos grupos $\mathrm{CH}_{3}$. Segundo a literatura $^{[12,13]}$, a presença dessas bandas de absorção confirma a intercalação do sal de amônio entre as camadas da argila.

\section{Análise de DRX}

A Figura 2 mostra as análises de DRX das bentonitas não modificada (BENT), sódica (BENT-Na) e modificada organicamente (BENT-org).

$\mathrm{O}$ difratograma de raios $\mathrm{X}$ da $\operatorname{BENT}$ (A) revela o pico característico (plano (001)) da bentonita em $2 \theta=5,84^{\circ}$. O difratograma aponta ainda que essa amostra de bentonita possui como impureza o quartzo, representado pelos picos em $2 \theta=20,10^{\circ}$, $21,11^{\circ}$ e $26,82^{\circ[11]}$. Os difratogramas de raios $\mathrm{X}$ das argilas (A, B e C) evidenciam que ocorreram mudanças no deslocamento do pico de difração característico (plano (001)) da BENT natural $\left(2 \theta=5,84^{\circ}\right)$ com os dois tratamentos empregados para o processo de troca catiônica. Essas modificações aparecem na Tabela 1, que apresenta a posição do pico de difração característico (plano (001)) (20) da BENT, da BENT-Na e da BENT-org e suas respectivas distâncias interplanares.

O pico característico (plano (001)) da BENT em $2 \theta=5,84^{\circ}$ corresponde a uma distância interplanar de 15,13 Å. Resultados semelhantes foram encontrados por Santos et al. ${ }^{[1]}$.

$\mathrm{Na}$ análise de DRX da BENT-Na, observou-se uma diminuição da distância interplanar de 15,13 $\AA$ (BENT natural) para 12,61 $\left(2 \theta=7,01^{\circ}\right)$, sugerindo a troca dos cátions (cálcio e potássio) presentes na argila pelo íon $\mathrm{Na}^{+}$, o qual possui um tamanho menor que os outros dois cátions. Estes resultados sugerem a obtenção de uma argila com o espaço intercamadas mais homogêneo, o que facilita a reação de substituição dos cátions inorgânicos pelos os íons orgânicos. Rodrigues et al. ${ }^{[14]}$ também observaram uma redução na distância interplanar da bentonita sódica $(13,68 \AA$ A em relação à bentonita natural $(14,02 \AA)$.

A BENT-org apresentou dois picos em $2 \theta=4,83$ e $7,02^{\circ}$, correspondendo a valores de distâncias interplanares de 18,29 e $12,59 \AA$. Este resultado $\left(2 \theta=4,83^{\circ}\right)$ confirma a intercalação do cloreto de cetiltrimetilamônio entre as lamelas da bentonita. $\mathrm{O}$ pico em $2 \theta=7,02^{\circ}$ está possivelmente relacionado a alguma quantidade de argila não intercalada que permaneceu na mesma posição da BENT-Na.

Os difratogramas de raios $\mathrm{X}$ do $\mathrm{PP}$ puro e dos compósitos com a bentonita natural e modificada organicamente (PP/BENT e PP/BENT-org) estão representados nas Figuras 3 e 4.

O PP apresentou picos de difração em $2 \theta=13,52^{\circ} ; 16,33^{\circ}$; $17,98^{\circ}$ e $21,19^{\circ}$, que correspondem aos planos (110), (040), (130) e (111) do cristalito da fase cristalina $\alpha$ do PP, respectivamente. Os valores encontrados foram muito próximos dos picos relatados

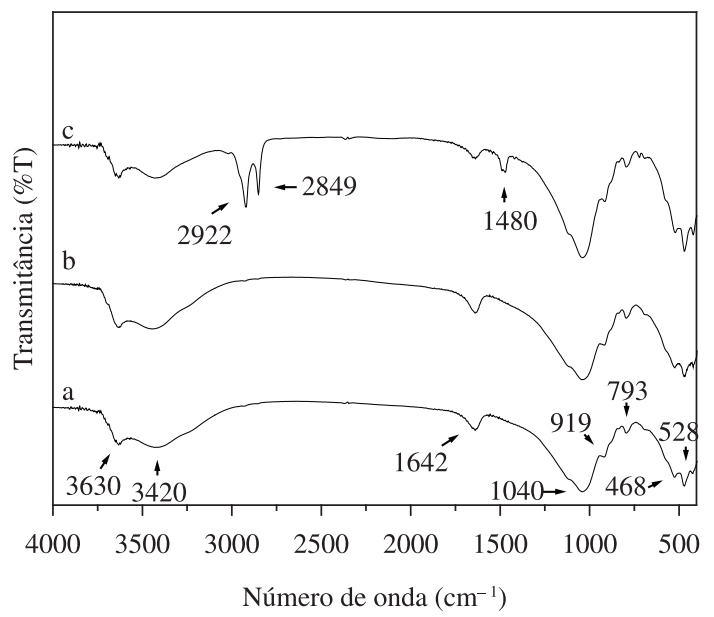

Figura 1. Espectro de FTIR das argilas BENT (a), da BENT-Na (b) e da BENT-org (c).

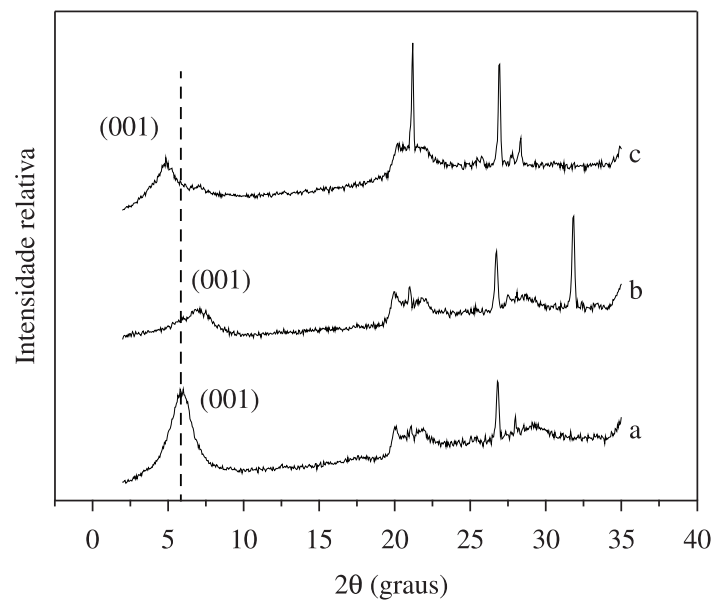

Figura 2. Difratogramas de raios X das argilas BENT (a), BENT-Na (b) e BENT-org (c).

Tabela 1. Pico de difração e distância interplanar da BENT, da BENT-Na e da BENT-org.

\begin{tabular}{lccc}
\hline Amostras & & $\mathbf{2 \theta}$ (graus) & Distância interplanar $(\AA)$ \\
\hline BENT & & 5,84 & 15,13 \\
BENT-Na & & 7,01 & 12,61 \\
BENT-org & $1^{\circ}$ pico & 4,83 & 18,29 \\
& $2^{\circ}$ pico & 7,02 & 12,59 \\
\hline
\end{tabular}


na literatura ${ }^{[15]}$. O cristalito da fase $\alpha$ é a forma principal para compósitos de PP com baixos teores de argila, porém, em alguns casos, pode haver o aparecimento de outros picos de difração. A forma cristalina $\beta$ encontra-se na faixa de $2 \theta$ entre 16,0 e $17,0^{\circ}$ e a forma cristalina $\gamma$ entre 19,2 e $20,5^{\circ[15]}$.

Os compósitos apresentaram os mesmos picos que o polímero, na faixa de $2 \theta=10$ a $30^{\circ}$, indicando que eles também contêm apenas a fase cristalina $\alpha$. Contudo, foi observada uma mudança na intensidade das reflexões em relação à matriz polimérica. Ellis et al. ${ }^{[16]}$ observaram resultados semelhantes e atribuíram a ocorrência da modificação na natureza cristalográfica do PP, à presença da argila.

A Tabela 2 apresenta o valor do pico principal (001) da bentonita natural (BENT) e da bentonita modificada organicamente (BENT-org) e sua respectiva distância interplanar nos compósitos.

Para o compósito PP/1\% em massa BENT não foi possível visualizar nenhum pico, provavelmente devido ao baixo teor de carga presente nesse material ${ }^{[17]}$. Os resultados da Tabela 2 ainda mostraram que houve uma pequena diminuição na distância interplanar dos compósitos com a argila sem tratamento ( 3 e $5 \%$ em massa de BENT), indicando a não intercalação do polímero nas galerias da $\operatorname{argila}^{[18]}$. Segundo Araújo et al. ${ }^{[19]}$, tal resultado pode ser atribuído a pouca afinidade do PP com a argila natural. Ainda, de acordo com Paiva et al. ${ }^{[7]}$ esse deslocamento do pico principal (001) da BENT para ângulos maiores também pode ser atribuído à compactação da argila diminuindo assim o espaço basal entre as camadas da argila. Também não foi verificada a presença de picos para o compósito $\mathrm{PP} / 1 \%$ em

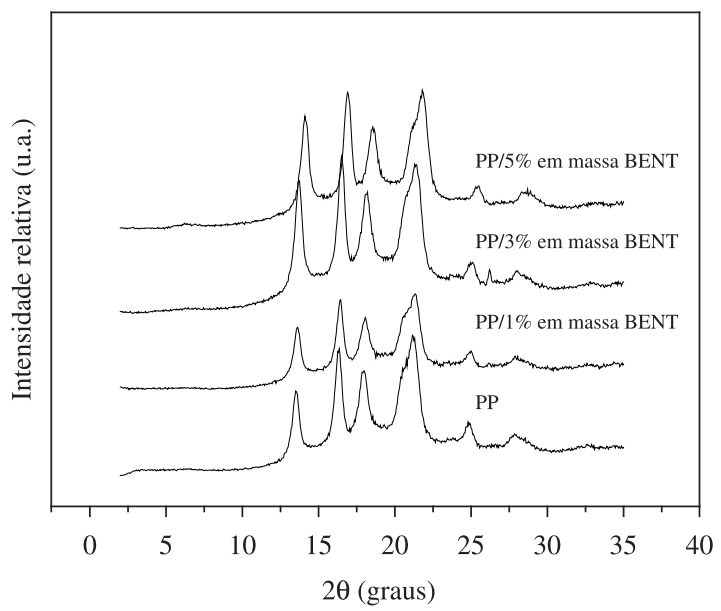

Figura 3. Difratogramas de raios $\mathrm{X}$ do PP e dos compósitos PP/BENT.

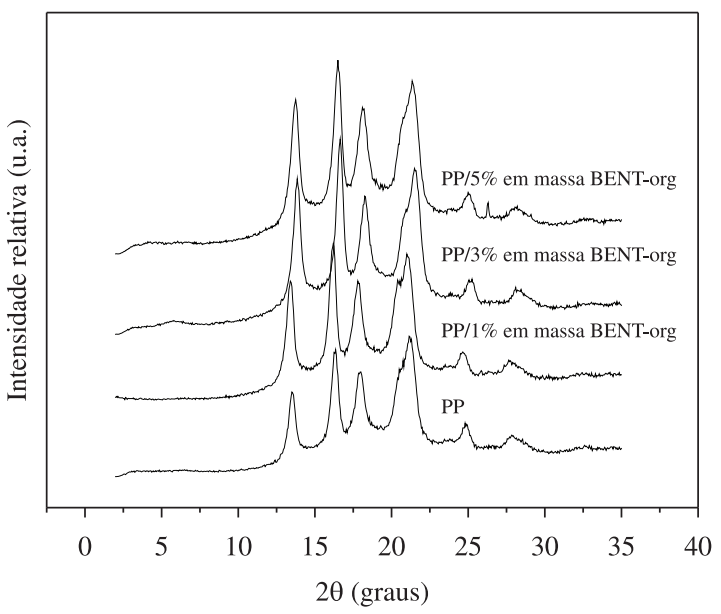

Figura 4. Difratogramas de raios $\mathrm{X}$ do $\mathrm{PP}$ e dos compósitos PP/BENT-org. massa BENT-org. Os outros dois compósitos preparados com a BENT-org apresentaram deslocamentos do pico principal da argila. O compósito $\mathrm{PP} / 3 \%$ em massa BENT-org indicou picos em $2 \theta=3,16^{\circ}$, $4,29^{\circ}$ e $6,38^{\circ}$ e para o compósito PP/5\% em massa BENT-org foram visualizados dois picos, em $2 \theta=3,06^{\circ}$ e $5,77^{\circ}$. A presença desses picos em diferentes posições, deslocados para menores ângulos, provavelmente está associada à intercalação das cadeias do polímero entre as camadas da $\operatorname{argila}^{[20]}$

\section{Análise de DSC}

A Tabela 3 exibe os valores da temperatura de fusão cristalina $\left(\mathrm{T}_{\mathrm{m}}\right)$, da temperatura de cristalização ocorrida durante o resfriamento $\left(\mathrm{T}_{\mathrm{cc}}\right)$ e do grau de cristalinidade $\left(\mathrm{X}_{\mathrm{c}}\right)$ do polímero puro e dos compósitos PP/BENT e PP/BENT-org.

Os resultados da Tabela 3 mostram que não ocorreram variações significativas na temperatura de fusão cristalina $\left(\mathrm{T}_{\mathrm{m}}\right)$ dos compósitos estudados em função da modificação da argila. Foi observado que os sistemas com $1 \%$ em massa de BENT e de BENT-org apresentaram os menores valores de $\mathrm{T}_{\mathrm{m}}\left(159^{\circ} \mathrm{C}\right)$. De acordo com Causin et al. ${ }^{[21]}$, essa queda na $T_{m}$ pode estar relacionada com o melhor grau de dispersão da argila nesses materiais. Foi observado que o pico de

Tabela 2. Valores do pico de difração e da distância interplanar da BENT e da BENT-org nos compósitos PP/BENT e PP/BENT-org.

\begin{tabular}{lcc}
\hline \multicolumn{1}{c}{ Amostras } & 2 $\theta$ (graus) & Distância interplanar $(\mathbf{\AA})$ \\
\hline PP/1\% em massa BENT & - & - \\
PP/3\% em massa BENT & 6,56 & 13,47 \\
PP/5\% em massa BENT & 6,24 & 14,16 \\
PP/1\% em massa BENT-org & - & - \\
& 3,16 & 27,96 \\
PP/3\% em massa BENT-org & 4,29 & 20,60 \\
& 6,38 & 13,85 \\
PP/5\% em massa BENT-org & 3,06 & 28,87 \\
& 5,77 & 15,32 \\
\hline
\end{tabular}

Tabela 3. Propriedades térmicas do PP e dos compósitos PP/BENT e PP/BENT-org.

\begin{tabular}{lccc}
\hline \multicolumn{1}{c}{ Amostras } & $\mathbf{T}_{\mathbf{m}}\left({ }^{\circ} \mathbf{C}\right)$ & $\mathbf{T}_{\mathrm{cc}}\left({ }^{\circ} \mathbf{C}\right)$ & $\mathbf{X}_{\mathrm{c}}(\boldsymbol{\%})$ \\
\hline PP & $157 / 163$ & 108 & 72 \\
PP/1\% em massa BENT & 159 & 116 & 74 \\
PP/3\% em massa BENT & 162 & 117 & 70 \\
PP/5\% em massa BENT & 161 & 122 & 77 \\
PP/1\% em massa BENT-org & 159 & 115 & 76 \\
PP/3\% em massa BENT-org & 161 & 119 & 81 \\
PP/5\% em massa BENT-org & 161 & 119 & 76 \\
\hline
\end{tabular}

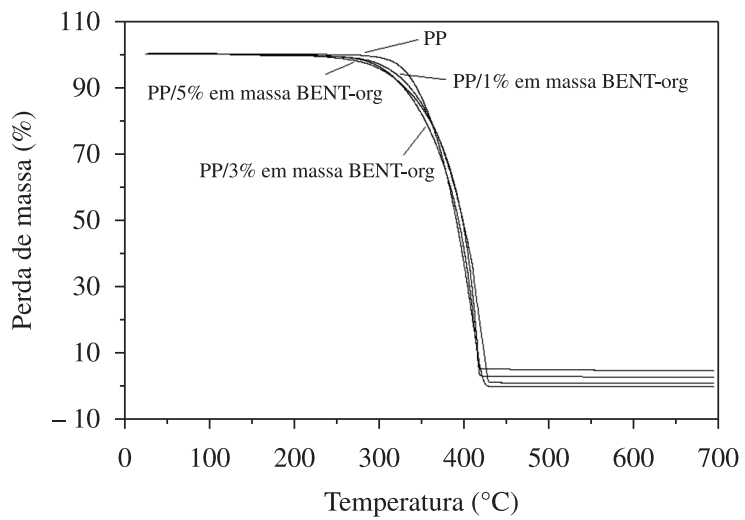

Figura 5. Medidas de TGA para o PP puro e os compósitos com a BENT-org. 
Tabela 4. Valores de degradação térmica do PP, masterbaches e dos compósitos com a BENT e BENT-org.

\begin{tabular}{lcccc}
\hline \multicolumn{1}{c}{ Amostras } & $\mathbf{T}_{\text {inicial }}\left({ }^{\circ} \mathbf{C}\right)$ & $\mathbf{T}_{\text {máxima }}\left({ }^{\circ} \mathbf{C}\right)$ & Teor nominal de BENT (\% em massa) & Teor real de BENT (\% em massa) \\
\hline PP & 363 & 411 & - & - \\
Masterbach PP/BENT & 388 & 427 & 25 & 34,1 \\
PP/1\% em massa BENT & 362 & 413 & 1 & 1,1 \\
PP/3\% em massa BENT & 363 & 416 & 3 & 3,4 \\
PP/5\% em massa BENT & 368 & 418 & 5 & 5,3 \\
Masterbach PP/BENT-org & 426 & 444 & 25 & 30,7 \\
PP/1\% em massa BENT-org & 361 & 417 & 1 & 1,1 \\
PP/3\% em massa BENT-org & 377 & 416 & 3 & 2,8 \\
PP/5\% em massa BENT-org & 384 & 415 & 5 & 4,7 \\
\hline
\end{tabular}

$\mathrm{T}_{\text {inicial }}=$ temperatura inicial de degradação. $\mathrm{T}_{\text {máxima }}=$ temperatura máxima de degradação.

fusão cristalina do PP nos compósitos passou de bimodal para monomodal, indicando que a argila pode estar auxiliando a formação de cristais mais homogêneos ${ }^{[22]}$. Todos os compósitos apresentaram um aumento na $\mathrm{T}_{c c}$, indicando que o argilomineral pode ter atuado como agente nucleante, modificando o tamanho e a forma dos cristais ${ }^{[17]}$. Os compósitos com menores teores de BENT (1 e 3\% em massa) não apresentaram variação na $\mathrm{T}_{c c}, 116$ e $117^{\circ} \mathrm{C}$, respectivamente. Já o compósito $\mathrm{PP} / 5 \%$ em massa BENT apresentou o maior valor de $\mathrm{T}_{\mathrm{cc}}\left(122^{\circ} \mathrm{C}\right)$, provavelmente devido ao maior teor real de carga incorporado (5,3\% em massa de BENT) em relação aos outros materiais, conforme observado na análise de TG. Os compósitos com a BENT-org também mostraram maiores valores de $\mathrm{T}_{\mathrm{cc}}$ quando comparados ao polímero puro. Os compósitos com 1, 3 e $5 \%$ em massa de BENT-org apresentaram valores de $\mathrm{T}_{\mathrm{cc}}$ de 115,119 e $119{ }^{\circ} \mathrm{C}$, respectivamente. Chafidz et al. ${ }^{[23]}$ também observaram um aumento na $\mathrm{T}_{\mathrm{cc}}$ do $\mathrm{PP}\left(113{ }^{\circ} \mathrm{C}\right)$ com a adição de $5 \%$ em massa de montmorilonita organofílica $\left(126^{\circ} \mathrm{C}\right)$ e atribuíram esse aumento ao efeito nucleante promovido pela argila.

$\mathrm{O}$ grau de cristalinidade $\left(\mathrm{X}_{\mathrm{c}}\right)$ dos compósitos com menores teores de BENT (1 e 3\% em massa) não sofreu variação significativa em relação ao polímero puro. Esses compósitos apresentaram valores de $\mathrm{X}_{\mathrm{c}} 74$, e $70 \%$, respectivamente. O compósito $\mathrm{PP} / 5 \%$ em massa BENT mostrou um aumento de $6,9 \%$ no $X_{c}$ em relação ao PP puro $\left(X_{c}=77 \%\right)$. Os valores de $X_{c}$ dos compósitos $\mathrm{PP} / 1 \%$ em massa BENT-org e PP/5\% em massa BENT-org não variaram (76\%). Já, no compósito com $3 \%$ em massa de BENT-org, verificou-se um aumento de $12,5 \%$ em relação ao polímero puro. Esses resultados indicam que a presença de 5 e $3 \%$ em massa de BENT e BENT-org, respectivamente, parecem aumentar o efeito de nucleação acelerando o processo de cristalização ${ }^{[24]}$. Modesti et al. ${ }^{[25]} \mathrm{em}$ um estudo de PP/montmorilonita organofílica, observaram um aumento considerável no grau de cristalinidade do nanocompósito com 5\% em massa de carga $\left(X_{c}=50,9 \%\right)$ em relação ao polímero puro $\left(X_{c}=28,1 \%\right)$, sendo atribuído à nucleação ocasionada pela argila.

\section{Análise de TG}

A Figura 5 mostra as curvas de TGA obtidas para o PP puro e para os compósitos preparados com a BENT-org. Os termogramas mostram que a presença da argila tratada interfere na estabilidade térmica das amostras.

A Tabela 4 expõe os valores de degradação térmica do PP, masterbaches e dos compósitos com a BENT in natura e BENT-org.

$\mathrm{O}$ masterbach preparado com BENT apresentou $\mathrm{T}_{\text {inicial }}$ de $388 \mathrm{e} \mathrm{T}_{\text {máxima }}$ de $427^{\circ} \mathrm{C}$, mostrando que este concentrado é mais estável termicamente que o polímero puro. Já o masterbach com BENT-org apresentou $\mathrm{T}_{\text {inicial }}$ e $\mathrm{T}_{\text {máxima }}$ de 426 e $444{ }^{\circ} \mathrm{C}$, respectivamente, cujos valores são ainda maiores que a $\mathrm{T}_{\text {inicial }}$ e a $\mathrm{T}_{\text {máxima }}$ do PP.
A presença da argila sem tratamento, BENT, nos teores de 1 e $3 \%$ em massa, não modificou a $\mathrm{T}_{\text {inicial }}$ dos compósitos $\left(362\right.$ e $363{ }^{\circ} \mathrm{C}$, respectivamente), em relação ao PP puro. Já o compósito $\mathrm{PP} / 5 \%$ em massa BENT apresentou um aumento na $\mathrm{T}_{\text {inicial }}$ de $5{ }^{\circ} \mathrm{C}$. A $\mathrm{T}_{\text {máxima }}$ do compósito $\mathrm{PP} / 1 \%$ em massa $\mathrm{BENT}$ não apresentou variação significativa $\left(413{ }^{\circ} \mathrm{C}\right)$. Os compósitos com maiores teores de BENT (3 e 5\% em massa) mostraram um aumento de 5 e $7{ }^{\circ} \mathrm{C}$, respectivamente, quando comparados ao PP puro. Othman et al. ${ }^{[26]}$ atribuem a melhora na estabilidade térmica de compósitos de PP com bentonita a presença de óxidos metálicos na argila, tais como dióxido de silício, alumínio, ferro e magnésio.

Para os compósitos com a BENT-org houve uma melhora na $\mathrm{T}_{\text {inicial }}$ apenas para aqueles com maiores teores de carga. O compósito $\mathrm{PP} / 1 \%$ em massa BENT-org apresentou $\mathrm{T}_{\text {inicial }}$ de $361{ }^{\circ} \mathrm{C}$, sendo bem próxima à encontrada para o polímero puro. Já os compósitos $\mathrm{PP} / 3 \%$ em massa BENT-org e $\mathrm{PP} / 5 \%$ em massa BENT-org tiveram uma $\mathrm{T}_{\text {inicial }}$ de 377 e $384{ }^{\circ} \mathrm{C}$, respectivamente. Esse comportamento foi observado por Yu-Hai et al. ${ }^{[27]}$ que verificaram uma melhora de 16 e $34{ }^{\circ} \mathrm{C}$ na $\mathrm{T}_{\text {inicial }}$ de nanocompósitos de PP com 5 e $10 \%$ em massa de montmorilonita organofílica, respectivamente. Os autores atribuíram essa melhora ao efeito de barreira provocado pelas camadas bem dispersas da organoargila, dificultando a difusão de produtos voláteis e também do calor através do material polimérico. As $\mathrm{T}_{\text {máxima }}$ dos três compósitos com 1, 3 e $5 \%$ em massa de BENT-org foram de 417,416 e $415{ }^{\circ} \mathrm{C}$, respectivamente. Ou seja, levemente superiores à observada para o PP puro.

A Tabela 4 também mostra os valores reais de argila que foram incorporados durante o processamento e estes resultados mostram que os teores reais de argila ficaram próximos aos pretendidos (teóricos).

\section{Conclusão}

A argila organofílica foi obtida a partir de uma argila bentonítica nacional sintetizada com o sal de amônio quaternário, cloreto de cetiltrimetilamônio. Os resultados mostraram a presença dos grupos característicos do sal e a intercalação deste entre as camadas da argila, a partir das técnicas de FTIR e DRX.

Os difratogramas de raios $X$ dos compósitos com 3 e $5 \%$ em massa de BENT-org evidenciaram a presença de picos em diferentes posições deslocados para regiões de baixo ângulo, sugerindo a possível intercalação das cadeias do polímero entre as camadas da argila.

Não houve variação significativa na $T_{m}$ dos compósitos em função da modificação da argila. Entre os sistemas estudados os materiais com $1 \%$ em massa de BENT e de BENT-org apresentaram os menores valores de $\mathrm{T}_{\mathrm{m}}$. Todos os compósitos apresentaram um aumento na $\mathrm{T}_{\mathrm{cc}}$, sugerindo que o argilomineral pode ter atuado como agente nucleante. 
A incorporação da argila ao PP teve influência na estabilidade térmica do polímero. Entre os sistemas estudados os mais estáveis foram aqueles contendo $5 \%$ em massa de BENT e 3 e $5 \%$ em massa de BENT-org.

\section{Agradecimentos}

Os autores agradecem ao Conselho Nacional de Desenvolvimento Científico e Tecnológico (CNPq), à Coordenação de Aperfeiçoamento de Pessoal de Nível Superior (CAPES), à Suzano Petroquímica, à Tratamento de Resíduos de Belford Roxo (Tribel), à Koleta Ambiental S.A. e ao Centro de Reciclagem Rio (CRR).

\section{Referências Bibliográficas}

1. Sarkar, M.; Dana, K.; Ghatak, S. \& Banerjee, A. - Bull. Mater. Sci., 31, p.23 (2008). http://dx.doi.org/10.1007/s12034-008-0005-5

2. Benetti, E. M.; Causin, V.; Marega, C.; Marigo, A.; Ferrara, G.; Ferraro, A.; Consalvi, M. \& Fantinel, F. - Polymer, 46, p.8275 (2005). http:// dx.doi.org/10.1016/j.polymer.2005.06.056

3. Wang, Y.; Huang, Syh-W. \& Guo, Jiang-Y. - Polym. Compos., 30, p.1218 (2009). http://dx.doi.org/10.1002/pc.20681

4. Díaz, V. F. R.; Souza S. P. \& Souza S. H. - Quim. Ind., 5, p.33 (1992).

5. Santos, P. S. - "Ciência e Tecnologia de Argilas", v.1, 2.ed., Edgard Blücher, São Paulo (1989).

6. Villaluenga, J. P. G.; Khayet, M.; López-Manchado, M. A.; Valentin, J. L.; Seoane, B. \& Mengual, J. I. - Eur. Polym. J., 43, p.1132 (2007). http://dx.doi.org/10.1016/j.eurpolymj.2007.01.018

7. Paiva, L. B.; Morales, A. R. \& Guimarães, T. R. - Polímeros, 16, p.136 (2006). http://dx.doi.org/10.1590/S0104-14282006000200014

8. Patel, H. A.; Joshi, G. V.; Pawar R. R.; Bajaj H. C. \& Jasra, R. V. - Polym. Compos., 31, p.399 (2010).

9. Oliveira, M. F. L.; Oliveira, M. G. \& Leite, M. C. A. M. - Polímeros, 21, p.78 (2011). http://dx.doi.org/10.1590/S0104-14282011005000015

10. Boder, G. - "Structural Investigations of Polymers", Ellis Horwood, New York (1991).

11. Santos, C. P. F.; Melo, D. M. A.; Melo, M. A. F. \& Sobrinho, E. V. - Cerâmica, 48, p.178 (2002). http://dx.doi.org/10.1590/S036669132002000400002

12. Ramos Filho, F. G. R.; A'Vvila Junior, M. A.; Santana, L. L.; Melo, T. J. A. \& Silva, S. M. L. - Matéria, 10, p.24 (2005).
13. Araújo, E. M.; Melo, T. J. A.; Oliveira, A. D.; Araújo, H. L. D.; Araújo, K. D. \& Barbosa, R. - Polímeros, 16, p.38 (2006). http://dx.doi. org/10.1590/S0104-14282006000100010

14. Rodrigues, A. W.; Brasileiro, M. I.; Araújo, W. D.; Araújo, E. M., Neves, G. A. \& Melo, T. J. A. - Polímeros, 17, p.219 (2007). http:// dx.doi.org/10.1590/S0104-14282007000300011

15. Nam, P. H.; Maiti, P.; Okamoto, M.; Kotaka, T. \& Hasegawa, N. - Polymer, 42, p.9633 (2001). http://dx.doi.org/10.1016/S00323861(01)00512-2

16. Ellis, T. S. \& D’Angelo, J. S. - J. Appl. Polym. Sci., 90, p.1639 (2003). http://dx.doi.org/10.1002/app.12830

17. Nogueira, R.F. - "Preparação de compósito de polipropileno/ montmorilonita e caracterização por RMN multinuclear", Tese de Doutorado, Universidade Federal do Rio de Janeiro, Brasil (2004).

18. Wang, L. \& Wilkie, A. - Polym. Degrad. Stabil., 80, p.171 (2003). http://dx.doi.org/10.1016/S0141-3910(02)00399-3

19. Araújo, S. S.; Paiva, G. P.; Carvalho, L. H. \& Silva, S. M. L. - Matéria, 9, p.426 (2004).

20. Dong, Y. \& Bhattacharyya, D. - Compos. Part A, 39, p.1177 (2008). http://dx.doi.org/10.1016/j.compositesa.2008.03.006

21. Causin, V.; Marega, C.; Saini R.; Marigo, A. \& Ferrara, G. - J. Therm. Anal. Calorim., 90, p.849 (2007). http://dx.doi.org/10.1007/s10973006-8205-y

22. Brandão, L.S. - "Síntese e caracterização de nanocompósitos de PET com fosfatos híbridos de zircônio lamelares", Tese de Doutorado, Universidade Federal do Rio de Janeiro, Brasil (2006).

23. Chafidz, A.; Ali, M.; Al-haj \& Elleithy, R. - J. Mater. Sci., 46, p.6075 (2011). http://dx.doi.org/10.1007/s10853-011-5570-0

24. Olewnik, E.; Garman, K. \& Czerwiński, W. - J. Therm. Anal. Calorim., 101, p.323 (2010). http://dx.doi.org/10.1007/s10973-0100690-3

25. Modesti, M.; Lorenzetti, A.; Bon, D. \& Besco, S. - Polym. Degrad. Stab., 91, p.672 (2006). http://dx.doi.org/10.1016/j. polymdegradstab.2005.05.018

26. Othman, N.; Ismail, H. \& Mariatti, M. - Polym. Degrad. Stab., 91, p. 1761 (2006). http://dx.doi.org/10.1016/j.polymdegradstab.2005.11.022

27. Yu-Hai, S.; Yuan-Fang, L. \& De-Min, Jia. - Polym. Compos., 29, p.357 (2008). http://dx.doi.org/10.1002/pc.20395

Enviado: 20/07/11

Reenviado: 16/11/11

Aceito: $21 / 12 / 11$ 